\title{
Experimental Group
}

National Cancer Institute

\section{Source}

National Cancer Institute. Experimental Group. NCI Thesaurus. Code C161323.

A study population that receives the intervention that is the focus of the study. 